\title{
CHANGES IN COASTAL SEDIMENT DYNAMICS DUE TO MANAGED REALIGNMENT
}

\author{
LUCIANA S. ESTEVES ${ }^{1}$, JON J. WILLIAMS ${ }^{2}$
}

1. Faculty of Science and Technology, Bournemouth University, Talbot Campus, Poole, BH12 5BB,UK. lesteves@bournemouth.ac.uk

2. Mott MacDonald, Mott MacDonald House, 8-10 Sydenham Road, Croydon, CRO 2EE, UK. jon.williams@mottmac.com

\begin{abstract}
Consolidation of the ecosystem services approach and concerns about climate change impacts are leading to a paradigm shift in the management of coastal erosion and flooding risk. Working with nature approaches aiming to restore the adaptive capacity of environments to respond to dynamic conditions are now promoted in a growing number of local and national strategies. In England, for example, Shoreline Management Plans foresee $10 \%$ of the coastline to be realigned by 2030 and $15 \%$ by 2060 . Despite over 100 projects implemented in Europe, only few studies discuss the effects of managed realignment on coastal and estuarine sediment dynamics. This paper presents a conceptual model for the longer term evolution within and adjacent to management realignment sites and contrasts with evidence from published field data.
\end{abstract}

\section{Introduction}

In the $21^{\text {st }}$ century, consolidation of the ecosystem services approach and concerns about climate change impacts are leading to a paradigm shift in the management of coastal erosion and flooding risk (e.g. Temmerman et al. 2013; Esteves 2014). Understanding and working with nature, especially to restore the adaptive capacity of environments to respond to dynamic conditions, is now underpinning an increasing number of initiatives based on the concepts of 'creating space for nature' (e.g. the Dutch Room for the River, the British Making Space for Water and the Flemish Sigma Plan), often implemented through different mechanisms of managed realignment (Esteves 2014).

In England, for example, Shoreline Management Plans foresee $550 \mathrm{~km}$ (10\%) of the coastline length to be realigned by 2030 (creating 6,200 ha of coastal habitat); only around $66 \mathrm{~km}$ were realigned since 1991 (Committee on Climate Change 2013). Although there is a growing literature on some aspects of managed realignment, only few studies focus on sediment dynamics and even fewer on the implications for flood risk management. The understanding of the long-term evolution of managed realignment sites is still deficient (e.g. French 2006; Rotman et al. 2008; Esteves and Thomas 2014; Ni et al. 2014). 
Managed realignment through removal or breach of defences can cause important changes in the hydrodynamic conditions at and adjacent to the project site, influencing the tidal prism within the estuary and the erosion and deposition patterns in the intertidal zone (e.g. Friess et al. 2014). The evolution of realignment sites and the effects on adjacent areas depend on a number of factors intrinsic to the characteristic of the managed realignment project (volume and flow of water exchange in/out of the site; elevation in relation to the tidal range) and the surrounding physical environment (estuarine or open coast, sediment type and availability, sea level changes, interactions with vegetation and human-induced changes etc.). Based on the current knowledge about the effects of managed realignment on sediment dynamics, conceptual models for the longer term evolution within and adjacent to the sites will be presented and contrasted with evidence available in the literature.

\section{Defining 'Managed Realignment'}

In the literature, the term 'managed realignment' is more often used by European authors; however, definitions have varied through time and regionally. The term is inconsistently used; sometimes synonymous with a range of other terms (e.g. managed retreat, set back, de-embankment, depolderisation, controlled reduced tide etc.), while at other times each term reflect different concepts. Esteves (2014) clarifies the terminology by explaining the most common applications of the various terms and proposing a definition for managed realignment that is widely applicable to most uses:

"managed realignment is a soft engineering approach aiming to promote (socio-economic, environmental and legal) sustainability of coastal erosion and flood risk management by creating opportunities for the realisation of the wider benefits provided by the natural adaptive capacity of coastlines that are allowed to respond more dynamically to environmental change. Therefore, 'managed' refers to take purposefully actions, to plan, implement and monitor projects; and 'realignment' refers to the position of the shoreline and/or the line of defences" (Esteves 2014, p. 28).

Therefore, managed realignment becomes a general term that encompasses the range of methods based on the principles of 'creating space for water', including: removal of defences, breach of defences, realignment of defences (landward or seaward), controlled tidal flow (including regulated tidal exchange, RTE, and controlled reduced tide, CRT) and managed retreat (Esteves 2014). The main characteristics of the five types of managed realignment methods are indicated in Table 1. This article focuses specifically on managed realignment resulting in the landward displacement of the shoreline, implemented mainly 
through breach or realignment of defences; which are the dominant type of implementation method in Europe (Table 2).

Table 1. Managed Realignment Implementation Methods (adapted from Esteves 2014).

\begin{tabular}{|c|c|c|c|c|c|}
\hline Characteristic & 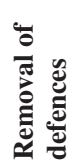 & 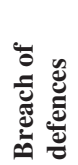 & 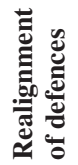 & 冚 & 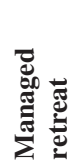 \\
\hline \multicolumn{6}{|l|}{$\begin{array}{l}\text { Extended sections of coastal defences are } \\
\text { removed }\end{array}$} \\
\hline \multicolumn{6}{|l|}{ Coastal defence is artificially breached } \\
\hline \multicolumn{6}{|l|}{ Defence is allowed to breach naturally } \\
\hline \multicolumn{6}{|l|}{$\begin{array}{l}\text { Construction of new line of defence or } \\
\text { upgrading secondary line of defence }\end{array}$} \\
\hline \multicolumn{6}{|l|}{ Sluices and culverts restore tidal flow } \\
\hline Project involves flood control areas & & & & CRT & \\
\hline Planned removal of people and assets at risk & & & & & \\
\hline
\end{tabular}

Black $=$ primary characteristic $;$ grey $=$ secondary/optional characteristics.

Table 2. Managed Realignment Projects in Europe.

\begin{tabular}{lccl}
\hline \multicolumn{1}{c}{ Country } & $\begin{array}{c}\text { Number of } \\
\text { projects }\end{array}$ & $\begin{array}{c}\text { Total area } \\
\text { (ha) }\end{array}$ & \multicolumn{1}{c}{ Implementation Method } \\
\hline Belgium & 15 & $2,743.6$ & Breach: 1; Removal: 1; Realignment: 8; CRT: 5 \\
Denmark & 2 & 206.0 & Breach: 2 \\
France & 4 & 484.0 & Breach: 1; Removal: 1; RTE: 1; Retreat: 1 \\
Germany & 29 & $5,066.7$ & Breach: 12; Removal: 13; Realignment: 1; RTE: 3 \\
Netherlands & 11 & $1,086.0$ & Breach: 7; Realignment: 3; CRT: 1 \\
Spain & 1 & 23.0 & Removal: 1 \\
UK & 54 & $2,275.6$ & Breach: 15; Removal: 2; Realignment: 19; RTE: 18 \\
\hline Total & 116 & $11,884.9$ & \\
\hline
\end{tabular}


Table 2 shows the number of managed realignment projects identified to date in Europe (as listed in Esteves 2014) per country and type of implementation and the total realigned area in each country. Note that CRT and RTE are types of controlled tidal restoration. Managed realignment projects are also found outside Europe, but compiling a list is a difficult task due to the range of terminology used. Terms such as active habitat restoration (e.g. Bowron et al., 2009), tidal hydrology restoration (NOAA, 2010) or simply tidal marsh restoration (e.g. van Proosdij et al., 2010; Brand et al., 2012) are used, but may also refer to habitat restoration projects purely focused on habitat or biodiversity restoration; therefore, not all are 'managed realignment' as they lack the planning aspects concerning flood and erosion management.

\section{Sediment Dynamics and Managed Realignment in the Literature}

Aspects concerning managed realignment are increasingly featured in the published literature. A simple keyword search using relevant online databases (i.e. Science Direct and Web of Science) currently identifies over 300 titles containing 'managed realignment' or other of the most commonly used terms (e.g. 'managed retreat'). The inconsistent use of terminology adds complexity to the literature search; therefore, the information provided here should be considered illustrative of publications currently available (excluding grey literature). A refined analysis (on January 2015) identified a total of 143 titles containing managed realignment in the title, abstract or keywords and only other 34 publications actually addressing aspects of managed realignment. Of the 177 'relevant' titles, only 73 included 'sediment' in the title, abstract or keywords and merely 34 presented data measured at realigned sites.

Considering that 116 managed realignment projects have been implemented or are under construction in Europe (Table 2), it is surprising how little has been published about sediment at the project sites. This is of special concern due to the relevance of sedimentary processes to the overall success of managed realignment. In reality, sediment dynamics is the main focus of only eight of the 34 articles. Usually, sedimentation or sediment characterisation appears as secondary aspect of studies on biogeochemistry (13 articles), saltmash development (six articles), macro-invertebrates or benthic infauna (five articles). Furthermore, publications are also limited in geographical coverage: 25 articles (73\%) cover projects in England, especially in the Blackwater Estuary (15 publications) and the Freiston Shore (six); five publications present data measured in a CRT project in the Scheldt estuary (Belgium); and the remaining articles refer to projects in Germany, Spain, USA and Canada. 


\section{Impacts of Managed Realignment on Estuarine dynamics}

Only few authors have discussed the impacts of managed realignment on estuarine morphodynamics, especially on the long-term. Some studies are based on theoretical concepts of estuarine evolution (e.g. French 2006; Pye and Blott 2014), others describe changes in drainage channels and adjacent intertidal area following seawall breaching (e.g. Freiss et al. 2014; Ni et al. 2014), while modelling approaches have been used to predict long-term ( $>50$ years) evolution of realigned sites (Spearman 2011; Ni et al. 2014). An increasing number of publications discuss the functional equivalency of recreated sites compared with natural ecosystems (e.g. Mossman et al. 2012). However, very little attention has been given to how the evolution of the realigned may affect flood risk.

Importantly, the impacts resulting from managed realignment will depend on many factors, including: the characteristics of the estuary (flood/ebb dominated; sediment rich/starved etc.); the size of the realigned area in relation to the estuary size; the location of the project(s) within the estuary; and the characteristics of the realigned site (e.g. type of soil, elevation within the tidal range). Therefore, all generalisations must be carefully considered due to the limited direct application to dissimilar sites. The effects of managed realignment on sediment dynamics and implications to flood risk are summarised next.

\section{Increase in Tidal Prism}

Through breaching or removal of flood defences, tidal flow is restored to a previously embanked area leading to an increase in tidal prism. The realigned site acts as a floodwater storage area, i.e. the volume of water that floods the site helps alleviating flooding elsewhere along the estuary (e.g. when a storm surge prevents river discharge resulting in enhanced water levels in the estuary). On the other hand, increases in tidal prism result in increased current velocities at the breach and downstream channels that now have to facilitate the exchange of larger volumes of water. Enhanced currents may influence tidal asymmetry favouring ebb tidal flows locally. In the long-term, the tidal prism tends to decrease due to accumulation of sediment (e.g. Warm Springs, San Francisco Bay, Williams et al. 2002) and saltmarsh development in the realignment site. However, this process may be slow or prevented in sediment starved systems.

\section{Changes in the Morphology of the Drainage Channels}

Increased upstream tidal prism and associated enhanced current velocities result in deepening and enlargement of the drainage channel downstream. The morphological changes occur until the drainage system reaches a dynamic equilibrium with the tidal prism. Although relationships between tidal prism and 
channel morphology have been modelled, predictions of channel evolution depend on empirically defined coefficient and exponent (e.g. Hughes 2002), which vary with the scale of the system, tidal range, salinity, vegetation, and sediment characteristics (e.g. Williams et al. 2002). The required field data rarely exist (Williams et al. 2002; Vandenbruwaene et al. 2012), and often values defined for other areas are applied for systems largely different (e.g. cohesive vs. non-cohesive). Such practice may lead to large errors in the prediction of optimal breach width and channel cross-sectional area in managed realignment projects, as reported by Friess et al. (2014) for Freiston Shore.

When projects cause major changes in tidal prism, erosion due to the growth and evolution of the drainage system can be considerable and persistent, as observed for over 13 year in Warm Springs, San Francisco Bay (Williams et al. 2002). In contrast, the length and cross-sectional area of channels fronting the 8 ha CRT project in the Scheldt estuary (Belgium) reached equilibrium within 4 years (Vandenbruwaene et al. 2012). The following changes were observed after breaching at Freiston Shore (Friess et al. 2014): (a) the spring tidal prism increased $776,398 \mathrm{~m}^{3}$; (b) all breach channels rapidly increased in width within the first 2.5 months (the central breach width enlarged from $2 \mathrm{~m}$ to $32 \mathrm{~m}$ ); (c) the cross-sectional area of the breach channels enlarged up to $5200 \%$ in four years (the central breach channel expanded from $2 \mathrm{~m}^{2}$ to $107.6 \mathrm{~m}^{2}$ ); (d) the three drainage creeks seawards of the realignment site showed a considerable headward erosion of up to $400 \mathrm{~m} \mathrm{a}^{-1}$ (Symonds and Collins 2007), while the adjacent creeks showed very little change in the same period; and (e) ephemeral creek systems developed over two years as a response to the sheet flow resulting from the excess water exceeding the existing drainage capacity; they silted up in the following year as the sheet flow disappeared (Symonds and Collins 2007).

The magnitude of changes in the drainage network at Freiston was not foreseen by the modelling undertaken for the project design. The velocities of the flood current at the breaches ( $2.5 \mathrm{~m} \mathrm{~s}^{-1}$ at the south breach) and the volume of water entering the site during the equinoctial spring tide after the breaching resulted in a prolonged inundation $(12 \mathrm{~h})$ and an ebbing phase over 2.5 times longer than the flood (Symonds and Collins 2007). This extended water retention was attributed to the inadequate size of the breach channels to drain the increased tidal prism (Freiss et al. 2014) and the elevation of the realigned area being lower than the saltmarshes fronting the site (Symonds and Collins 2007).

\section{Altered Accretion and Erosion Patterns}

Managed realignment will cause changes in sediment deposition and erosion patterns; however whether changes are local and short-lived or important across the estuary will depend on a number of factors, including the changes described 
above. Most managed realignment projects aim to create a relatively sheltered intertidal area where sediment accumulates driving elevation changes that favour saltmarsh development. In such cases, it is expected that the newly created intertidal areas will initially evolve to mudflats and, through vertical accretion, the areas higher in the tidal range will be colonised by saltmarshes. Colonisation by vegetation will promote further sediment deposition leading to a reduction of wave energy and current speeds. This usually occurs where high concentration of suspended sediments exists. The combination of sediment accretion and vegetation cover enhances the natural coastal protection reducing the risk of flooding to inland areas.

On the other hand, the morphological adjustment of drainage channels at the breach and seawards result in fast erosion of the intertidal area in front of the breaches. For example, an estimated $62,000 \mathrm{~m}^{3}$ of sediment was eroded in four years following enlargement of the drainage network in front of the breaches at Freiston Shore (Friess et al. 2014). Using mineral magnetic fingerprinting, Rotman et al. (2008) have demonstrated that 54\% of the sediment deposited within the Freiston realignment originates from the erosion of the established saltmarshes seaward of the site and 19\% from adjacent mudflats. Part of the sediment eroded from the intertidal area seaward of the breaches seems to be transported to the realigned site by flood tides. Rotman et al. report unpublished results from sedimentation plates showing a reduction in average accretion within the established saltmarshes since the breaching, with erosion reaching 16 $\mathrm{mm} \mathrm{a}^{-1}$ at seaward locations. Also, rapid siltation of downstream oyster beds provide evidence that part of the material eroded is transported seawards.

Considering the findings of Rotman et al. (2008), and assuming similar sediment pathways occurring at other sites, it is possible to assume that: (a) saltmarsh/mudflat erosion will reduce as the drainage channels reach geomorphic equilibrium with the tidal prism, resulting in the reduction of sedimentation rates within the realignment site; or (b) erosion in the external intertidal area continues in the long-term (e.g. enhanced by sea level rise) supplying sediment into the realignment site, but increasing exposure of the remaining seawall. As the establishment of newly created saltmarsh inside the realigned area is likely to take longer than the erosion of the established saltmarsh, a net loss of saltmarshes is likely to occur due to the realignment.

Based on a combination of field measurements and modelling for the Freiston realignment, Ni et al. (2014) suggest a conceptual model for the evolution of intertidal areas seaward of realignment sites. The authors identify three phases: (1) after breaching, rapid erosion occurs in the mid-intertidal area due to headward erosion of drainage channels and the development of new channels due to sheet flow. The sediment is transported seawards by the dominant ebb 
tides and deposited in the low intertidal flats creating a concave profile in the mid-flats and a convex profile in the lower areas; (2) once the drainage channels are able to deal with the tidal discharge, the sheet flow and associated erosion ceases, the mid-intertidal stabilise; the flood tide is enhanced and the lower intertidal area starts to erode, with sediments potentially moving landward to accrete the upper areas and the realignment site; and (3) after decades, the drainage channels reach morphologic equilibrium and the intertidal profile regain characteristics similar to pre-breaching. Field measurements between October 2003 and October 2004 at Freiston Shore indicate a temporal variation in mean grain size along the intertidal profile seaward of the realignment site, which seems to be greater at the lower intertidal areas, where higher proportion of sand correlate with increased rates of erosion ( $\mathrm{Ni}$ et al. 2014).

Rates of erosion are also influenced by the shear strength of the soils, which is higher in old compacted soils than in recent deposits. Vandenbruwaene et al. (2012) reports that rapid deposition at sites of lowest elevation facilitates headward erosion of drainage channels due to the low resistance offered by the water saturated deposits. Only once the flow is concentrated in the developed channels, the compacted and resistant soils start to erode. Therefore, channel deepening may be slowed due to the higher shear strength of the older deposits.

\section{Conceptual Models of Coastal Change Due to Managed Realignment}

The majority of managed realignment projects in the UK are of small dimensions ( $<20 \mathrm{ha})$ and implemented in estuaries highly impacted by humaninduced changes (e.g. land reclamation). Nevertheless, in most cases, the existing drainage channels seaward of embanked land are adjusted to current hydrodynamic conditions and have not changed considerably in previous decades (Figure 1a). Under such conditions, changes in tidal prism are small and managed realignment causes localised effects on hydrodynamic and sedimentation patterns (Figure 1b). Vertical accretion within the site (at decreasing rates with time) and short-term erosion due to drainage creek development at the breaches are often observed (e.g. van Proosdij et al. 2010; Vandenbruwaene et al. 2012), corresponding to the rapid adjustment phase after breaching described by $\mathrm{Ni}$ et al. (2014). Following tidal restoration, mudflats will develop within the site (Figure 1b), dominating through time if site elevation is low and unfavourable for the development of saltmarshes (Figure 1c). Saltmarshes will develop if elevation, sedimentation rates and inundation frequency and duration are favourable (Figure 1e).

In the first years following the breaches, the rapid morphological adjustments dominate in both sediment-rich and starved estuaries. 


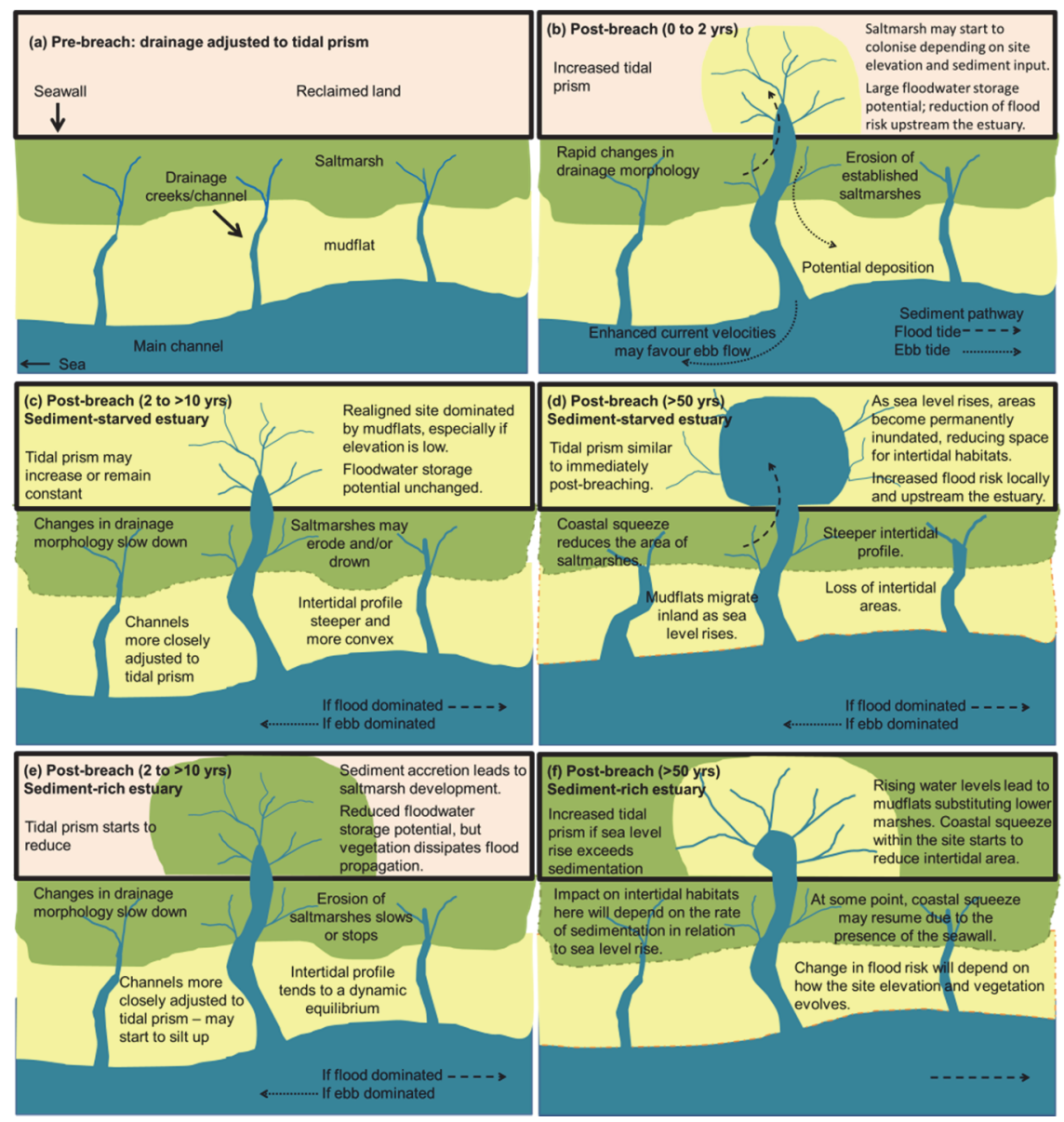

Fig. 1. Conceptualisation of the evolution of managed realignment sites and adjacent intertidal area showing: pre-breach site (a), short-term changes post-breaching (b); and medium (c) and long-term (d) changes for a sediment-starved and a sediment-rich estuary (e, f).

Although small individual projects may not cause great impact beyond the local level, many small projects within an estuarine system may have the same impact on tidal prism as a large project. This effect, however, is not well discussed in the literature. Another potential morphological change mentioned only briefly in the literature concern the formation or modifications in shape and volume of tidal deltas (e.g. Pye and Blott 2014) due to changes in flow velocities, direction of dominating tidal currents and erosion/accretion patterns. The development of an ebb delta, for example, has affected tidal exchange through the breach at Medmerry (in south England, currently the largest open coast realignment in the UK). 
In large projects, the changes shown in Figure $1 \mathrm{~b}$ are likely to occur following seawall breaching, but the magnitude, duration and rates of change may be enhanced as greater morphological adjustments are required following the increase in accommodation space and tidal prism. After the rapid adjustment phase, the rate of morphological change is reduced (Figure 1c, e), but can persist for over a decade (e.g. Williams et al. 2002). The changes that follow will depend on the concentration of suspended sediment, whether the estuary is ebb or flood dominated and the rate of sedimentation in relation to sea-level rise.

In sediment-starved areas (Figure 1c) or where sedimentation does not keep up with sea level rise (e.g. Spearman 2011), the tidal prims may increase (e.g. if enhanced flows facilitate exportation of sediment). The intertidal profile seaward of the realignment steepens (Spearman 2011; Ni et al. 2014) and the realigned sites may act as a flood storage area reducing flood risk in the upper estuary. However, increasing flood risk to nearby areas, due to profile steepening and increased water levels, is likely. In the long-term, some areas will become permanently inundated inside and outside the realigned site, and coastal squeeze may lead to a reduction of intertidal habitats (Figure 1d). These changes will lead to a long-term increase in flood risk across the estuary. If flood tides dominate, erosion of saltmarshes may provide sediment source to the realigned area, somewhat alleviating the impacts of rising sea levels.

In sediment-rich systems, the accommodation space is likely to be reduced through time due to increased sedimentation and potential development of saltmarshes (Figure 1e, f). In such cases, there is a reduction in flood storage space but vegetated areas dissipate wave energy and flood propagation, reducing flood risk in nearby areas. If sedimentation rates are similar to the rates of sealevel rise, the conditions shown in Figure 1e may be long lasting. However, changes are expected if sediment rates are slower or exceed sea level rise (Figure 1f). If sedimentation rates exceed sea-level rise, vertical accretion may favour succession from upper saltmarshes to freshwater habitats in places where high elevations prevent tidal inundation. Increased elevations will greatly reduce flood risk locally, but the reduction in accommodation space may enhance flood risk elsewhere in the estuary. If sea level is rising faster than sediment is accumulated, there will be a gradual increase in tidal prism and water levels, leading to drowning of lower saltmarshes, which will give place to mudflats (Figure 1f). Coastal squeeze will reduce the intertidal area in front of the remaining seawall and eventually act inside the realignment site, gradually increasing flood risk. Although representing improved flood risk management under certain conditions, some of the detrimental long-term changes described here are inflicted by the artificial constraint of hard engineering, which will pose a threat to the long-term sustainability of the sites. 


\section{Wider Implications}

There is little doubt that managed realignment must be seriously considered as a coastal management option. However, questions still arise concerning the costeffectiveness of some approaches of managed realignment, especially when compared with natural saltmarsh restoration. In many locations, the abandonment of reclaimed land associated with accidental breaching of defences or saltwater intrusion (see Almeida et al. 2014) resulted in the regeneration of saltmarshes with little or no active intervention. At these sites, species richness, composition and structure differ from natural adjacent saltmarshes even after 100 years from tidal restoration (Garbutt and Wolters 2008). However, studies indicate that similar differences, are also found in managed realignment sites despite active intervention and costly investments.

Arguments in favour of planning the breaching of defences concern controlling where, when and how changes in land cover and flooding and erosion patterns will occur to ensure unacceptable risks are avoided. Costly interventions to prepare the site pre-breaching are also justified in projects driven by legal requirements to compensate for loss of specific types of habitat. For example, measures to reduce land elevation and siltation may be implemented where there is a requirement to create a specific extension of mudflats (e.g. Pontee 2014)

Modelling approaches have been used to predict long-term morphological changes associated with managed realignment (e.g. Spearman 2011; Ni et al. 2014). Although such models may provide qualitative indication of long-term changes is key estuarine features, it is still to be demonstrated that models can reproduce the impacts from major flood events with the accuracy required for planning and risk management applications. Major flood events are responsible for most of sediment exchange between rivers, estuaries and the open coast (e.g. Williams et al. 2002) and key pulses of morphological change.

The unexpected erosion caused by the rapid growth of the channels at the managed realignment breaches in the Freiston project was attributed to an overwhelming volume of water retained within the site due to extreme high tides (e.g. Symonds and Collins 2007). The evolution of the drainage channel network at the site and the associated erosion and deposition patterns at the site and adjacent intertidal area are well documented (e.g. Symonds and Collins 2007; Rotman et al. 2008; Friess et al. 2012, 2014; Ni et al. 2014). However, the literature does not show evidence of attempts to test whether existing models are able to simulate the hydrologic and morphologic conditions using a hindcast approach. Before existing modelling approaches can be claimed as useful tool to predict morphological evolution over periods of 60-80 years, it is necessary to demonstrate their ability to reproduce the impacts of 'major' or extreme 
conditions at temporal and spatial scales relevant to inform design and management decisions. Currently, the lack of adequate monitoring data at spatial and temporal resolutions hinders the advance of knowledge that allow modelling advances required to support evidence-based management decisions (e.g. Esteves 2014; Pye and Blott 2014).

\section{Conclusion}

Managed realignment approaches are increasingly implemented to provide sustainable flood risk management with additional environmental benefits. Most projects are designed taking into consideration flood protection criteria. However, the literature provides little information about the effects of projects on hydrodynamics and the potential implications to changes in flood risk. Considering the scale in which managed realignment is planned in the future (e.g. UK), there is a need to better understand the longer-term impacts on coastal evolution and the likely implications to flood risk. Otherwise, we risk creating a legacy of coastal problems similar to the one we now face as a result of the "hard engineering era' of coastal protection. This paper clarifies the definition of managed realignment and summarises the current knowledge concerning sedimentation patters and morphological change at the site and adjacent intertidal areas. A conceptual model for the short, medium and long-term evolution of the sites is presented for sediment rich and sediment starved conditions.

\section{Acknowledgements}

Dr Esteves would like to thank the financial support of the Bournemouth University Fusion Funds that facilitated attendance to the Coastal Sediments conference. Dr Williams acknowledges the support from Mott MacDonald's Ports, Coastal and Offshore Group during the development of this work.

\section{References}

Bowron, T., Neatt, N., van Proosdij, D., Lundholm, J., and Graham, J. (2009). "Macro-Tidal Salt Marsh Ecosystem Response to Culvert Expansion," Restoration Ecology, 19(3), 307-322.

Brand, L.A.; Smith, L.M.; Takekawa, J.Y.; Athearn, N.D.; Taylor, K.; Shellenbarger, G.G.; Schoellhamer, D.H., and Spenst, R. (2012). "Trajectory of early tidal marsh restoration: Elevation, sedimentation and colonization of breached salt ponds in the northern San Francisco Bay," Ecological Engineering, 42, 19-29. 
Committee on Climate Change. (2013). "Managing the land in a changing climate. Chapter 5: Regulating services - coastal habitats," Adaptation SubCommittee Progress Report 2013, Committee on Climate Change, 92-107.

Esteves, L.S. (2014). "Managed realignment: is it a viable long-term coastal management strategy?" Springer, $136 \mathrm{p}$.

Esteves, L.S. and Thomas, K. (2014). "Managed realignment in practice in the UK: results from two independent surveys," Journal of Coastal Research, SI $70,407-413$.

French, P.W. (2006). "Managed realignment - The developing story of a comparatively new approach to soft engineering," Estuarine Coastal and Shelf Science, 67(3), 409-423.

Friess, D.A., Spencer, T., Smith, G.M., Möller, I., Brooks, S.M., and Thomson, A.G. (2012). "Remote sensing of geomorphological and ecological change in response to saltmarsh managed realignment, The Wash, UK," International Journal of Applied Earth Observation and Geoinformation, $18,57-68$.

Friess, D.A., Möller, I., Spencer, T., Smith, G.M., Thomson, A.G., and Hill, R.A. (2014). "Coastal saltmarsh managed realignment drives rapid breach inlet and external creek evolution, Freiston Shore (UK)," Geomorphology, $208,22-33$.

Hughes, S.A. (2002). "Equilibrium cross sectional area at tidal inlets," Journal of Coastal Research, 18, 160-174.

Garbutt, A., and Wolters, M. (2008). "The natural regeneration of salt marsh on formerly reclaimed land," Applied Vegetation Science, 11, 335-344.

Mossman, H.L., Davy, A.J., and Grant, A. (2012). "Does managed coastal realignment create saltmarshes with 'equivalent biological characteristics' to natural reference sites?" Journal of Applied Ecology, 49, 1446-1456.

NOAA (Restoration Center \& Coastal Services Center). (2010). "Returning the Tide, A Tidal Hydrology Restoration Guidance Manual for the Southeastern U.S., NOAA, Silver Spring, MD. Available from http://www.habitat.noaa.gov/partners/toolkits/tidal_hydro.html. 
Ni, W., Wang, Y.P., Symonds, A.M., and Collins, M.B. (2014). "Intertidal flat development in response to controlled embankment retreat: Freiston Shore, The Wash, UK," Marine Geology, 355, 260-273.

Pontee, N. (2014). "Accounting for siltation in the design of intertidal creation schemes," Ocean \& Coastal Management, 88, 8-12.

Pye, K., and Blott, S.J. (2014). "The geomorphology of UK estuaries: The role of geological controls, antecedent conditions and human activities," Estuarine, Coastal and Shelf Science, http://dx.doi.org/10.1016/j.ecss.2014.05.014

Rotman, R., Naylor, L., McDonnell, R., and MacNiocaill, C. (2008). "Sediment transport on the Freiston Shore managed realignment site: An investigation using environmental magnetism," Geomorphology, 100(3-4), 241-255.

Spearman, J. (2011). "The development of a tool for examining the morphological evolution of managed realignment sites," Continental Shelf Research, 31(10), S199-S210.

Symonds, A.M., and Collins, M.B. (2007). "The establishment and degeneration of a temporary creek system in response to managed coastal realignment: The Wash, UK," Earth Surface Processes and Landforms, 32, 1783-1796.

Temmerman, S., Meire, P., Bouma, T.J., Herman, P.M.J., Ysebaert, T., and De Vriend, H.J. (2013). "Ecosystem-based coastal defence in the face of global change." Nature, 504, 79-83.

van Proosdij, D., Lundholm, J., Neatt, N., Bowron, T., and Graham, J. (2010). "Ecological re-engineering of a freshwater impoundment for salt marsh restoration in a hypertidal system," Ecological Engineering, 36(10), 13141332.

Vandenbruwaene, W., Maris, T., Cox, T.J.S., Cahoon, D.R., Meire, P., and Temmerman, S. (2011). "Sedimentation and response to sea-level rise of a restored marsh with reduced tidal exchange: Comparison with a natural tidal marsh," Geomorphology, 130(3-4), 115-126.

Williams, P.B., Orr, M.K., and Garrity, N.J. (2002). "Geomorphic Design Tool for Tidal Marsh Channel Evolution in Wetland Restoration Projects," Restoration Ecology, 10(3), 577-590. 